\title{
Marking the un-markable: visible implant elastomer in wild juvenile snakes
}

\author{
Tom Major ${ }^{1}$, Devlan R Alkins ${ }^{1}$, Lauren Jeffrey ${ }^{1} \&$ Wolfgang Wüster $^{1}$
}

${ }^{1}$ Molecular Ecology and Fisheries Genetics Laboratory, School of Natural Sciences, Bangor University, Wales, UK

\begin{abstract}
Marking individuals is a key component of many ecological studies, but with some animals, such as juvenile snakes, it has proven problematic because of size constraints. This impedes our understanding of their habits in the wild. We marked juvenile Aesculapian snakes (Zamenis longissimus) in North Wales with visible implant elastomer (VIE), and recaptured them the following season. Our results demonstrate that the use of VIE is an effective marking method for small snakes, negating the need for tissue removal when marking. We suggest it represents a promising development in the ecological study of snakes, and is especially useful in species that undergo ontogenetic pattern changes.
\end{abstract}

Keywords: Capture-mark-recapture, ecology, tagging, fluorescent, ontogenetic change

$C^{3}$ apture-mark-recapture (CMR) studies are important in the collection of data on individual development, site fidelity, movement patterns, and abundance of individuals (Sanchez-Camara \& Booth, 2004; Krebs, 1989). As most CMR studies rely on distinguishing one individual from another, unique marks or patterns are key to an effective study. The marks must meet several fundamental criteria: the mark cannot be easily lost; it must not affect the survival of the individual; it must not affect the likelihood of recapture; and it must be recordable (Otis et al., 1978). Because of their small size and lack of limbs, juvenile snakes have been difficult to mark (Winne et al., 2006). As a result, the natural history and movement ecology of juvenile snakes remains poorly understood and represents a major knowledge gap in herpetology (Ferner \& Plummer, 2016).

There are many different methods by which a mark can be applied to snakes (Haines \& Modde, 1996; Powell \& Proulx, 2003), but most have drawbacks undermining their utility. Externally mounted tags can be shed or knocked off when the snake is active and may hinder the snake in its movement. Ventral scale clipping marks are less obtrusive to the animal, but can sometimes be confused due to new scars on the ventral side of the snake, and substantial regrowth of clipped tissue. The same is true for marks made with cauterising units. Passive integrated transponders (PIT) tags are the most reliable, albeit most expensive, method of identifying individual snakes. However, due to their size, PIT tags are unsuitable for use in smaller snakes.

Body colour and pattern can be used to identify individual snakes in some cases. However, both are susceptible to change in many species, where the pattern is altered or altogether lost as the individual ages (Creer, 2005; Sacchi et al., 2016; Lunghi et al., 2019). Head scalation can also be useful, but while changes in scalation are not common, ontogenic changes have been suggested in Vipera ursinii (Tomović et al., 2008), and changes due to injury have been seen in $V$. berus (Bauwens, Claus, \& Mergeay, 2018).

In this study we present a method for marking wildcaught, juvenile snakes, by application of visible implant elastomer (VIE). VIE is an inert, biocompatible polymer. The elastomer is injected as a liquid which cures into a pliable solid under the skin of the individual. The marks fluoresce under UV-B light and are externally visible. Whilst VIE has been criticised as unreliable in frogs (Brannelly, Chatfield, \& Richards-Zawacki, 2013), it has been used successfully in many different reptile and amphibian species including turtles (Anderson et al., 2015), lizards (Schmidt \& Schwarzkopf, 2010), and frogs (Bainbridge et al., 2015; Sapsford et al., 2014). VIE has also been used in small salamanders, including the eastern red-backed salamander (Plethodon cinereus) (Heemeyer, Homyack, \& Haas, 2007), the northern twolined salamander (Eurycea bislineata) (Bailey, 2004), and Webster's salamander (Plethodon websteri) (Mann \& Mann, 2017). Northern two-lined salamanders are small and slender, presenting similar difficulties to juvenile snakes. With regard to snakes, Hutchens et al. (2008) successfully implanted 18 corn snakes (Pantherophis guttutas), and showed the marks lasted over a year under lab conditions. In salamanders, the marks have been shown to last up to five years (Lunghi \& Bruni, 2018). However, there are no published studies that look at VIE as a viable method of marking free-living snakes. Here, we demonstrate the use of VIE as a simple, effective method for marking small wild snakes for use in CMR studies.

This study took place as part of a CMR study of 
introduced Aesculapian snakes (Zamenis longissimus) in Colwyn Bay, North Wales. Juveniles of this species sport a black and yellow chequered chin and ventral pattern which is unique to the individual, but, as that individual grows, these markings are completely lost, and the snake becomes olive-green to brown along its flanks and dorsum and yellow on the ventral scales. Without a reliable marking method for juvenile snakes it is therefore difficult to recognise an adult snake previously encountered as a juvenile. A mark scheme was generated using the software Salamarker (The Williams Lab, Purdue University; MacNeil, Dharmarajan, \& Williams, 2011). Twelve marking locations and two colours were selected, with each individual snake receiving marks in two of 12 locations producing 264 unique mark combinations (Fig. 1). A Visible Implant Elastomer Manual Injections Kit (Northwest Marine Technology, Inc) was used to mark the animals.

We marked wild juvenile snakes (snakes that weighed under $40 \mathrm{~g}$, and likely under three years old) $(\mathrm{N}=43)$ with two elastomer marks each from 21 April 2018 to 17 October 2018, using either fluorescent red or fluorescent yellow VIE, or one of each. We selected these colours to contrast with the dark base colour of the snakes. We used two mark sites per snake because we decided 264 combinations was enough for our purposes, as we did not anticipate capturing more than 264 juvenile snakes. The injection was made using a 29-gauge needle in the interstitial skin. A fold of loose skin was made by gently pinching the skin together dorsolaterally, creating a pocket for the needle to enter. The needle was directed anteriorly, and approximately $0.02 \mathrm{ml}$ were injected at each location, in a small 'stripe' three scales in length (Fig. 1). After application the marks were checked for external visibility under UV-B light. Marking took approximately four minutes per snake, including the counting of scales to determine mark site. The snakes were then released at their exact site of capture.

All snakes caught in the following season (April October 2019) were checked for VIE marks. Snakes were also compared to a photographic record of head and chin images to test whether any snakes had shed their marks, and if that movement of marks affected our ability to ID individuals. Seven individuals with elastomer marks were recaptured in 2019. The snakes were successfully identified using the position of the VIE marks along the body in accordance with the mark scheme. The snakes' identities were confirmed using photos of the individuals' unique chin pattern and head scalation. Snakes were recaptured an average of $377 \pm 36$ days after their initial capture (range $306-434$ days). Red marks could easily be seen in daylight, allowing quick identification of recaptures, but yellow marks were sometimes missed. Both red and yellow marks were easily recognisable using a UV-B light, under which the marks fluoresce (Fig. 1). In the 2019 season all unmarked juvenile snakes $(\mathrm{N}=27)$ were new to the study and there was no evidence of mark loss in any of the previously marked snakes. This was confirmed by comparison of photos of head scalation. All recaptured snakes grew between captures. See Table 1 for individual snake metrics.

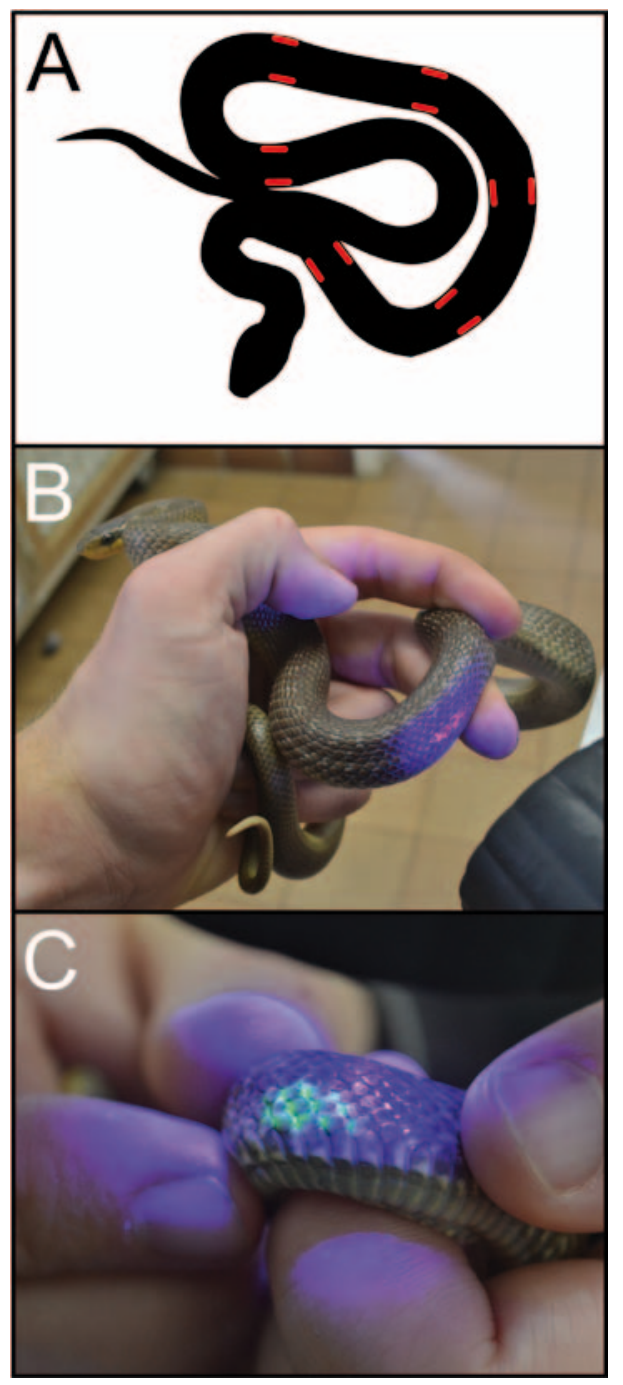

Figure 1. Examples of visible implant elastomer used in wild Aesculapian snakes (Zamenis longissimus). Photos were taken during brief measuring, snakes were not held in captivity; A) the approximate locations of the mark zones, with 12 possible locations in the elastomer mark scheme; B) the red mark shown under UV-B light 381 days after initial insertion (ZALO049); C) close up of yellow mark under UV-B 390 days after insertion (ZALO042).

Of the 14 marks applied to recaptured snakes, 13 remained intact at their initial application site. In one instance, however, the mark stretched dorsolaterally, both anterior and posterior of the mark site, for a total of 30 scales, approximately 15 each way. This did not overlap with other marks, as they were 20 scales apart. The mark was thickest at the original application site and became thinner as the elastomer travelled. We believe this to be a result of overapplication of the elastomer leading to dispersion prior to setting, or possibly, but less likely, poor mixing of elastomer and curing agent. Importantly, the mark had stretched, and not migrated elsewhere on the body. While the mark was still decipherable, minimising the amount of elastomer applied should avoid such complications.

The economics of VIE are comparable with those of PIT tags. A $6 \mathrm{ml}$ VIE kit costs $£ 250$ and will mark approximately 80 snakes with two marks (£3.12 per snake), with refill packs costing less than $£ 100$ ( $£ 1.25$ per 
Table 1. Metrics of individually marked Aesculapian snakes (Z. longissimus) captured in both 2018 and 2019, showing changes in mass and snout-vent length (SVL), and time between captures.

\begin{tabular}{|c|c|c|c|c|c|c|c|}
\hline Individual & Mass 2018 (g) & Mass $2019(\mathrm{~g})$ & $\begin{array}{l}\text { Increase in mass } \\
\text { (g) }\end{array}$ & SVL $2018(\mathrm{~mm})$ & SVL $2019(\mathrm{~mm})$ & $\begin{array}{c}\text { Increase in SVL } \\
(\mathrm{mm})\end{array}$ & $\begin{array}{c}\text { Days between } \\
\text { capture }\end{array}$ \\
\hline 20 & 9.84 & 12.29 & $2.45(25 \%)$ & 265 & 467 & 202 (76\%) & 366 \\
\hline 34 & 8.52 & 16.11 & 7.59 (89\%) & 244 & 292 & $48(20 \%)$ & 434 \\
\hline 36 & 29 & 49.96 & $20.96(72 \%)$ & 368 & 525 & 157 (43\%) & 373 \\
\hline 42 & 11.16 & 19.76 & $8.6(77 \%)$ & 290 & 345 & 55 (19\%) & 390 \\
\hline 45 & 10.24 & 11.89 & $1.65(16 \%)$ & 249 & 267 & $18(7 \%)$ & 392 \\
\hline 49 & 32.26 & 77.13 & 44.87 (139\%) & 407 & 506 & 99 (24\%) & 381 \\
\hline 54 & 11.97 & 13.35 & $1.38(12 \%)$ & 275 & 339 & $64(23 \%)$ & 306 \\
\hline
\end{tabular}

snake). For PIT tags, the cost will be around $£ 130$ for the tag reader, with the PIT tags costing around $£ 130$ for 50 snakes ( $f 2.60 /$ snake). VIE would be more costly when marking larger snakes, as larger amounts would have to be used to effectively mark individual snakes, so the use of PIT tags would be more economical in larger snakes.

In conclusion, our study has presented the first evidence of the long-term reliability of VIE tags in wild, juvenile snakes. This marking method will aid in addressing major knowledge gaps in the ecology of small, slender, and juvenile snakes, which were previously difficult or impossible to mark. Using VIE, these snakes can now be marked reliably, greatly enhancing the possibilities for future ecological studies. As our maximum time between captures was 434 days, the maximum time VIE marks can last in snakes is still unknown. We believe the evidence presented justifies the use of VIE in wild snakes, especially those too small for PIT tags, and those which undergo dramatic ontogenetic change in size and/ or colour pattern. Further work with both marked and unmarked snakes will better clarify any possible effects on snake fitness and survival.

\section{ACKNOWLEDGEMENTS}

This study was supported by the Knowledge Economy Skills Scholarships (KESS II - case number 80815) and the Welsh Mountain Zoo. We gratefully thank the staff of the Welsh Mountain Zoo for their invaluable support and assistance. This work took place with approval from the Bangor University Animal Welfare and Ethics Review Board.

\section{REFERENCES}

Anderson, K. P., Byer, N. W., McGehee, R. J. \& Richards-Dimitrie, T. (2015). A new system for marking hatchling turtles using Visible Implant Elastomer. Herpetological Review 46, 2527.

Bailey, L. L. (2004). Evaluating elastomer marking and photo identification methods for terrestrial salamanders: Marking effects and observer bias. Herpetological Review 35, 38-41.

Bainbridge, L., Stockwell, M., Valdez, J., Klop-Toker, K., Clulow, S., Clulow, J. \& Mahony, M. (2015). Tagging tadpoles: Retention rates and impacts of visible implant elastomer (VIE) tags from the larval to adult amphibian stages. Herpetological Journal 25, 133-140.

Bauwens, D., Claus, K. \& Mergeay, J. (2018). Genotyping validates photo-identification by the head scale pattern in a large population of the European adder (Vipera berus). Ecology and Evolution 8, 2985-2992.

Brannelly, L. A., Chatfield, M. W. H. \& Richards-Zawacki, C. L. (2013). Visual implant elastomer (VIE) tags are an unreliable method of identification in adult anurans. Herpetological Journal 23, 125-129.

Creer, D. A. (2005). Correlations between ontogenetic change in color pattern and antipredator behavior in the racer, Coluber constrictor. Ethology 111, 287-300.

Ferner, J. W. \& Plummer, M. V. (2016). Marking and measuring reptiles. In Reptile Ecology and Conservation: A Handbook of Techniques (pp. 45-58).

Haines, G. B. \& Modde, T. (1996). Evaluation of marking techniques to estimate population size and first-year survival of Colorado squawfish. North American Journal of Fisheries Management 16, 905-912.

Heemeyer, J. L., Homyack, J. A. \& Haas, C. A. (2007). Retention and readability of visible implant elastomer marks in eastern red-backed salamanders (Plethodon cinereus). Herpetological Review 38, 425-428.

Hutchens, S. J., Deperno, C. S., Matthews, C. E., Pollock, K. H. \& Woodward, D. K. (2008). Visible implant fluorescent elastomer: A reliable marking alternative for snakes. Herpetological Review 39, 301-303.

Krebs, C. J. (1989). Ecological Methodology. New York: Harper \& Row.

Lunghi, E. \& Bruni, G. (2018). Long-term reliability of Visual Implant Elastomers in the Italian cave salamander (Hydromantes italicus). Salamandra 54, 283-286.

Lunghi, E., Giachello, S., Mulargia, M., Dore, P.P., Cogoni, R. \& Corti, C. (2019). Variability in the dorsal pattern of the Sardinian grass snake (Natrix natrix cetti) with notes on its ecology. Acta Herpetologica 14, 141-145.

MacNeil, J. E., Dharmarajan, G. \& Williams, R. N. (2011). Salamarker: A code generator and standardized marking system for use with visible implant elastomers. Herpetological Conservation and Biology 6, 260-265.

Mann, T. M., \& Mann, D. L. (2017). Seasonal migration by a terrestrial salamander, Plethodon websteri (Webster's salamander). Herpetological Conservation and Biology 12, 96-108.

Otis, D. L., Burnham, K. P., White, G. C. \& Anderson, D. R. (1978). Statistical Inference from capture data on closed animal populations. Wildlife Monographs 62, 3-135.

Powell, R. A. \& Proulx, G. (2003). Trapping and marking terrestrial mammals for research: Integrating ethics, performance 
criteria, techniques, and common sense. ILAR Journal 44, 259-276.

Sacchi, R., Scali, S., Mangiacotti, M., Sannolo, M. \& Zuffi, M.A.L. (2016). Digital identification and analysis. In: Kenneth Dodd, C.J. (eds) Reptile Ecology and Conservation, Oxford University Press, 59-72, Oxford

Sapsford, S. J., Roznik, E. A., Alford, R. A. \& Schwarzkopf, L. (2014). Visible Implant Elastomer marking does not affect short-term movements or survival rates of the treefrog Litoria rheocola. Herpetologica 70, 23.

Sanchez-Camara, J. \& Booth, D.J. (2004). Movement, home range and site fidelity of the weedy seadragon Phyllopteryx taeniolatus (Teleostei: Syngnathidae). Environmental Biology of Fishes 70, 31-41.
Schmidt, K. \& Schwarzkopf, L. (2010). Visible implant elastomer tagging and toe-clipping: Effects of marking on locomotor performance of frogs and skinks. Herpetological Journal 20, 99-105.

Tomović, L., Carretero, M. A., Ajtíc, R. \& Crnobrnja-Isailovíc, J. (2008). Evidence for post-natal instability of head scalation in the meadow viper (Vipera ursinii) - Patterns and taxonomic implications. Amphibia Reptilia 29, 61-70.

Winne, C. T., Willson, J. D., Andrews, K. M., \& Reed, R. N. (2006). Efficacy of marking snakes with disposable medical cautery units. Herpetological Review 37, 52-54.

Accepted: 9 April 2020 